\title{
Diagnosis of Coronavirus disease by measuring serum concentrations of IL- 6 and blood Ferritin
}

\section{Parviz Yazdanpanah}

Yasuj University of Medical Sciences

\section{Farzad Vafaei}

Yasuj University of Medical Sciences

\section{Saeed Javdansirat}

Yasuj University of Medical Sciences

Jalal pouranfard

Yasuj University of Medical Sciences

Sajad Afrouz ( $\nabla$ sajadafrouz@yums.ac.ir)

Yasuj University of Medical Sciences https://orcid.org/0000-0002-0713-3741

\section{Research}

Keywords: COVID-19, Infection, Proinflammatory Cytokines, Interleukin-6, Ferritin

Posted Date: September 15th, 2020

DOI: https://doi.org/10.21203/rs.3.rs-74750/v1

License: (a) (i) This work is licensed under a Creative Commons Attribution 4.0 International License. Read Full License 


\section{Abstract}

Objectives: Coronavirus disease 2019 (COVID-19) associated by infection and high death rate. The unresolved questions about the fatality rate of COVID-19 is most probably related to cytokine storm syndrome. There is currently no specific medication. Understanding the pathogenic pathway of this disease will lead to production of treatment and decreases of death rate. The aim of this study is to investigate changes of peripheral blood parameters (Interleukin- 6 and Ferritin) in COVID-19 patients, which may be beneficial in the management of patients.

Methods: In this case-control study, we collected data of 270 subjects in two groups including 133 patients with severe type COVID-19 (case) and 137 patients with nonsevere (control) between March 20 and May 21,2020 , and the clinical symptoms and inflammatory indications of patients diagnosed by laboratory test in Shahid Jalil hospital of Yasuj University of medical Sciences were collected to explore potential markers for disease monitoring. The data were analyzed by SPSS software version 20. Descriptive statistics, T-test and bivariate correlation tests were used to analyze.

Results: The enrolled COVID-19 patients consisted of $53.4 \%$ males and $46.6 \%$ females with the medium age of $45.56 \pm 18.55$ years and there were $50.04 \%$ males and $49.6 \%$ females with the medium age of $45.59 \pm 17.0$ years for non COVID-19 patients. There was no significant difference in the age and sex ratio between two population under study.

The proportion interstitial abnormalities evidenced by CT imaging in COVID-19 patients was $91.0 \%$, while, $4.4 \%$ abnormalities was found in non COVID-19 patients. The frequency of positive RT-PCR test for case and control groups were $88.0 \%$ and $3.6 \%$, respectively.

The mean IL-6 and Ferritin levels and hematological parameters in two groups of patients with COVID-19 and non- COVID-19, were significantly different across all comparisons.

There was a direct positively correlated between serum level of IL-6, Ferritin levels and hematological parameters including WBC, Lymphocytes, Neutrophils and Hb, except for platelets (negatively correlate), with COVID-19.

Conclusions: In conclusion, inflammatory markers specifically IL-6 and Ferritin and hematological parameters (WBC, Lymphocytes, Neutrophils, Platelet and $\mathrm{Hb}$ ) were correlated with the severity of COVID19. Measurement of IL-6, Ferritin and hematological indices might be workable tests to diagnosis and prognosis of patients with COVID-19.

\section{Introduction}

Coronavirus disease 2019 (COVID-19) or the severe acute respiratory syndrome corona virus 2 (SARS-CoV2), it was first reported in December 2019 in Wuhan City, China(1). COVID-19 is an infectious disease by typical symptoms include dry cough, muscle aches or fatigue, high fever and shortness of breath with severe acute respiratory syndrome (ARDS) on CT scans (2-4). 
Coronavirus binds to the angiotensin-converting enzyme2 (ACE2) which is present on no immune cells, such as respiratory and endothelial cells and immune cells such as alveolar monocytes/macrophages(5), and can induce endogenous stress signals or mutations in the host genome and recruitment of inflammatory cells(6). In the defensive line, innate immunity senses microorganisms and release of cytokines, Chemokines and inflammatory mediators by immune cells, epithelial cells and etc. in pathological conditions(7). The increase in specific cytokine production can be linked to an activation cascade and uncontrolled cytokine release; the cytokine storm(8). Although cytokines expression is strictly controlled by transcriptional and posttranscriptional mechanisms, but high-level concentrations of cytokines for a long time leads to chronic inflammatory diseases and widespread tissue damage including $\operatorname{ARDS}(9,10)$.

During a virus infection, the plasma concentration Interleukin (IL)-6, IL-1 and IL-10 were increased(11), especially, IL-6, which promptly stimulate the production of acute phase proteins in response to infections and tissue injuries (7). IL-6 alterations, reflect the presence and severity of inflammation, and they have long been used as a clinical Guideline for diagnosis and management of diseases. $(11,12)$.

Also, high levels of lactate dehydrogenase (LDH), and ferritin are suggestive due to the cytokine storm in Laboratory findings. Also, elevated Ferritin and Lactate dehydrogenase (LDH) levels due to cytokine storm syndrome have been reported in severe COVID-19 patients (13). In hospitalized patients, serum ferritin testwhich is widely available and affordable-is a good qualified screening tool for informing physicians of cytokine storm syndrome for COVID-19 patients(14).

In general, COVID-19 in infected people of all ages, can be implications on different organs as lungs, brain and nervous system and eventually, may lead to death (15). Therefore, diagnose and treatment of cytokine storm and infection by measuring serum concentrations of IL-6 and blood ferritin has become an important part of rescuing severe patients.

\section{Material And Methods}

\section{Samples Data collection}

In this case-control study, we collected data of 270 subjects in two groups including 133 patients with severe type COVID-19 (case) and 137 patients with non-severe (control), between March 20 and May 21, 2020 , and the clinical characteristics and inflammatory indications of patioents which diagnosed by laboratory test in Shahid Jalil hospital of Yasuj University of medical Sciences, were collected to explore potential markers for disease monitoring.

In this study, General and specific biosafety guidelines for diagnosis of COVID-19 was accordance with the WHO guidance. A confirmed positive case for COVID-19, was assessed by real-time reverse transcriptase polymerase chain reaction (RT-PCR) test from the nasopharyngeal or oropharyngeal swabs specimens. lonely laboratory confirmed cases were contained in this study, while disease diagnosed based on clinical presentation and CT imaging findings were excluded. 
In this study, demographic data, clinical symptoms, imaging examinations, previous nucleic acid test results, and other laboratory findings, CT Scanning, whole blood cell count and blood chemistry of patients were collected from electronic medical records using data collection forms. In addition, ferritin, lymphocyte subset and cytokine tests was analyzed in severe patients by Flow cytometry and ELISA detection.

\section{ELISA detection and Blood Count Test}

In this study, Complete Blood Count (CBC) Test, were measured using a Sysmex KX21 Hematology Analyzer (Block Scientific, Bohemia, NY, USA).

Serum concentrations of IL- 6 were also measured in in all COVID-19 and non COVID-19 samples. IL-6 levels were measured by the enzyme-linked immunosorbent assay (ELISA) kit (Gen-Probe, Diaclone France) as per the manufacturer's instructions.

Human serum ferritin concentrations were determined by using a diagnos- tic kit from Abbott Laboratories (Abbott Park, IL). All tests were performed according to the product manual.

\section{Statistical analysis}

All data were analyzed by descriptive statistics include: Chi-squared for categorical variables and averages and standard deviations for continuous data. Continuous variables were compared using the Student Ttest between groups. The Pearson's correlation coefficient ( $r$ ) was used to understand the correlations between various laboratory findings. Data were carried out by SPSS software version 20. For all statistical analysis, $p$-value less than 0.05 (typically $\leq 0.05$ ) is statistically significant.

\section{Ethical considerations}

Since, there was no threat for participants and its results were only used to improve diagnisis planning of covid19; so we obtained informed consent. It should also be noted that in this study, we avoided mentioning any names, titles or characteristics that cause the loss of privacy of the participants, and the participants were clearly informed of the possible uses of the results.

\section{Results}

\section{Demographic and clinical characteristics}

The enrolled COVID-19 patients(case) consisted of 53.4\% (71) males and $46.6 \%$ (62) females with the medium age of $45.56 \pm 18.55$ years old and there were $50.04 \%$ (69) males and $49.6 \%$ (68) females with the medium age of $45.59 \pm 17.0$ years old for non COVID-19 patients (control).

There was no statistical evidence for different association in the ages and sex between two case and control groups (Table 1). 
The percentage of lung abnormalities on CT imaging in COVID-19 patients was 91.0\% (121), while, 4.4\% (6) abnormalities was found in imaging of non COVID-19 patients $(p<0.05)($ Table 1$)$.

Also, Table1 shows the frequency of RT-PCR test results in the case and control samples. The frequency of positive results for case and control groups were $88.0 \%(117 / 133)$ and $3.6 \%(5 / 137)$, respectively.

Table 1

Describe the clinical characteristics o of patients with COVID-19 and non- COVID-19

\begin{tabular}{|c|c|c|c|c|}
\hline \multicolumn{2}{|l|}{ Variables } & $\begin{array}{l}\text { Case } \\
\mathrm{N}(\%)\end{array}$ & $\begin{array}{l}\text { Control } \\
\mathrm{N}(\%)\end{array}$ & P-Value \\
\hline \multirow[t]{2}{*}{ Gender } & Male & 71(53.4) & $69(50.4)$ & \multirow[t]{2}{*}{0.628} \\
\hline & Female & $62(46.6)$ & $68(49.6)$ & \\
\hline \multirow[t]{3}{*}{ Age } & $40>$ yrs & $65(48.9)$ & $58(42.3)$ & \multirow[t]{4}{*}{0.480} \\
\hline & $40-60$ yrs & $40(30.1)$ & $50(36.5)$ & \\
\hline & $60<y r s$ & $28(21.1)$ & $29(21.2)$ & \\
\hline Mean \pm SD & & $45.56 \pm 18.55$ & $45.59 \pm 17$ & \\
\hline \multirow[t]{2}{*}{ CT } & positive & $121(91.0)$ & $6(4.4)$ & \multirow[t]{2}{*}{0.000} \\
\hline & negative & $12(9.0)$ & 131(95.6) & \\
\hline \multirow[t]{2}{*}{ RT-PCR } & positive & $117(88.0)$ & $5(3.6)$ & \multirow[t]{2}{*}{0.000} \\
\hline & negative & 16(12.0) & 132(96.4) & \\
\hline
\end{tabular}

\section{ELISA Detection And Blood Count Test}

Significant differences were found between the case and control groups on ELISA detections. These studies also reported the levels of serum IL-6 and Ferritin, which are especially high in COVID-19 patients $(283.53 \pm 115.21 \mathrm{pg} / \mathrm{ml}$ and $399.87 \pm 143.31 \mathrm{pg} / \mathrm{ml})$ compared to non-COVID-19 patients $(44.07 \pm$ $29.80 \mathrm{pg} / \mathrm{ml}$ and $150.63 \pm 93.44 \mathrm{pg} / \mathrm{ml})(\mathrm{p}<0.05)($ Table 2$)$.

Also, data analysis showed significant differences in hematological parameters (WBC, Lymphocyte, Neutrophil, Platelet and Hb) between COVID-19 patients and non- COVID-19 group $(p<0.05)($ Table 2$)$. 
Table 2

Comparison of the laboratory findings of patients with COVID-19 and nonCOVID-19.

\begin{tabular}{|c|c|c|c|c|}
\hline \multirow[t]{2}{*}{ Variables } & & Case & Control & \multirow[t]{2}{*}{ P-Value } \\
\hline & & $N(\%)$ & $\mathrm{N}(\%)$ & \\
\hline Ferritin & $\leq 240$ & $48(36.1)$ & 117(85.4) & \multirow[t]{3}{*}{0.000} \\
\hline$(\mathrm{pg} / \mathrm{ml})$ & $>240$ & $85(63.9)$ & $20(14.6)$ & \\
\hline Mean \pm SD & & $399.87 \pm 143.31$ & $150.63 \pm 93.44$ & \\
\hline IL-6 & $\leq 20$ & $3(2.3)$ & $56(40.9)$ & \multirow[t]{3}{*}{0.000} \\
\hline$(\mathrm{pg} / \mathrm{ml})$ & $>20$ & 130(97.7) & 81(59.1) & \\
\hline Mean \pm SD & & $283.53 \pm 115.21$ & $44.07 \pm 29.80$ & \\
\hline WBC & $<4$ & $0(0.0)$ & $5(3.6)$ & \multirow[t]{4}{*}{0.001} \\
\hline (UL) & $4-10$ & (83.5) 111 & 131(95.6) & \\
\hline \multirow[t]{2}{*}{ Mean \pm SD } & $>10$ & $22(16.5)$ & $1(0.7)$ & \\
\hline & & $8.56 \pm 1.50$ & $6.10 \pm 1.40$ & \\
\hline Lymphocyte & $<18$ & $15(11.3)$ & 17(12.5) & \multirow[t]{4}{*}{0.001} \\
\hline (\%) & $18-35$ & $50(37.6)$ & $85(62.0)$ & \\
\hline \multirow[t]{2}{*}{ Mean \pm SD } & $>35$ & $68(51.1)$ & $35(25.5)$ & \\
\hline & & $34.48 \pm 10.67$ & $30.60 \pm 9.90$ & \\
\hline Neutrophil & $<45$ & $2(1.5)$ & $22(16.1)$ & \multirow[t]{4}{*}{0.001} \\
\hline (\%) & $45-65$ & $25(18.8)$ & 82(59.8) & \\
\hline \multirow[t]{2}{*}{ Mean \pm SD } & $>65$ & 106(79.7) & $33(24.1)$ & \\
\hline & & $72.67 \pm 10.40$ & $58.87 \pm 12.06$ & \\
\hline Platelet & $\leq 150$ & $24(18.0)$ & $0(0.0)$ & \multirow[t]{4}{*}{0.001} \\
\hline$(\times 1000$ UL $)$ & $150-450$ & $109(82.0)$ & $39(90.7)$ & \\
\hline \multirow[t]{2}{*}{ Mean \pm SD } & $>450$ & $0(0.0)$ & $4(9.3)$ & \\
\hline & & $184.54 \pm 43.30$ & $256.97 \pm 81.11$ & \\
\hline $\mathrm{Hb}$ & $<12$ & $8(6.0)$ & 10(7.3) & \multirow[t]{4}{*}{0.000} \\
\hline$(\mathrm{mg} / \mathrm{dL})$ & $12-16$ & 64(48.1) & 113(82.5) & \\
\hline \multirow[t]{2}{*}{ Mean \pm SD } & $>16$ & $61(45.9)$ & $14(10.2)$ & \\
\hline & & $15.66 \pm 1.88$ & $14.32 \pm 1.55$ & \\
\hline
\end{tabular}


The means comparison of IL-6, Ferritin and hematological parameters in different groups were showed in Table 3. There was a high statistically significant in mean concentrations of IL-6, Ferritin, WBC, Lymphocyte, Neutrophil, Platelet and Hb, in COVID-19 group compared to non- COVID-19 group. All findings between two groups were significant at level $p<0.05$ (Table 3 ).

Table 3

The means comparison of IL-6, Ferritin and hematological parameters between COVID-19 and non- COVID-19 groups.

\begin{tabular}{|lllll|}
\hline Variables & Mean Difference & P-Value & \multicolumn{2}{c|}{ Cl(95\%) } \\
\cline { 4 - 5 } & & & Lower & Upper \\
\hline Ferritin & 156.19 & .000 & 129.69 & 182.70 \\
\hline IL-6 & 243.45 & .000 & 222.27 & 264.6 \\
\hline WBC & 2.45 & .000 & 2.10 & 2.80 \\
\hline Lymphocyte & 3.88 & .002 & 1.40 & 6.35 \\
\hline Neutrophil & 13.79 & .000 & 11.09 & 16.50 \\
\hline Platelet & -71.80 & .000 & -89.25 & -54.34 \\
\hline Hb & 1.34 & .000 & 0.93 & 1.75 \\
\hline
\end{tabular}

Data analysis revealed that there was a direct positively correlation between the serum levels of IL- 6 with Ferritin $(r=0.509, p=0.000)$ and hematological markers includes WBC $(r=0.539, p=0.000)$, Lymphocyte $(r$ $=0.197, p=0.001)$, Neutrophil $(r=0.431, p=0.000)$ and $\mathrm{Hb}(r=0.344, p=0.000)$, while it was an inverse correlation with Platelet $(r=-0.361, p=0.001)$, (Table 4).

Based on our assessment, a significant correlation was identified between the serum levels of Ferritin and the following parameters: direct positively correlation with IL-6 $(r=0.509, p=0.000), W B C(r=0.433, p=$ $0.000)$, Neutrophil $(r=0.420, p=0.000)$ and $\mathrm{Hb}(r=0.226, p=0.000)$, direct negatively correlation with Platelet $(r=-0.357, p=0.000)$ and non-correlation with Lymphocyte $(r=.076, p=.211)$ (Table 4).

In our study, a negative direct relationship was identified between Platelets with IL-6( $r=-0.361, p=0.000)$, Ferritin $(r=-0.357, p=0.000)$ and all hematological indices WBC $(r=-0.374, p=0.000)$, Lymphocyte $(r=-.159, p$ $=0.009)$, Neutrophil $(r=-0.272, p=0.000)$ and $\mathrm{Hb}(r=-0.280, p=0.000)$. (Table 4).

In addition, data analysis revealed that there was non-significant correlation in Lymphocyte with WBC ( $\mathrm{r}=$ $0.118, p=0.052)$, Neutrophil $(r=-0.071, p=0.243)$ and Ferritin $(r=-.076, p=0.211)$ (Table 4). 
Table 4. The Correlation between IL-6 and Ferritin and hematological parameters in COVID-19 patients.

\begin{tabular}{|c|c|c|c|c|c|c|c|c|}
\hline Variables & & Ferritin & IL-6 & WBC & Lymphocyte & Neutrophil & Platelet & $\mathrm{Hb}$ \\
\hline Ferritin & $\mathrm{R}$ & 1 & $\begin{array}{l}.509 \star \star \\
.000\end{array}$ & $\begin{array}{l}.433^{\star \star} \\
.000\end{array}$ & $\begin{array}{l}.076 \\
.211\end{array}$ & $\begin{array}{l}.420^{\star \star} \\
.000\end{array}$ & $\begin{array}{l}-.357^{\star \star} \\
.000\end{array}$ & $\begin{array}{l}.226^{\star \star} \\
.000\end{array}$ \\
\hline IL-6 & $\mathrm{R}$ & & 1 & $\begin{array}{l}.539 * * \\
.000\end{array}$ & $\begin{array}{l}.197 \star \star \\
.001\end{array}$ & $\begin{array}{l}.431^{\star *} \\
.000\end{array}$ & $\begin{array}{l}-.361^{\star *} \\
.000\end{array}$ & $\begin{array}{l}.344^{\star *} \\
.000\end{array}$ \\
\hline WBC & $\mathrm{R}$ & & & 1 & $\begin{array}{l}.118 \\
.052\end{array}$ & $\begin{array}{l}.491^{\star \star} \\
.000\end{array}$ & $\begin{array}{l}-.374^{\star *} \\
.000\end{array}$ & $\begin{array}{l}.320^{\star \star} \\
.000\end{array}$ \\
\hline Lymphocyte & $\mathrm{R}$ & & & & 1 & $\begin{array}{l}-.071 \\
.243\end{array}$ & $\begin{array}{l}-.159 * * \\
.009\end{array}$ & $\begin{array}{l}.234^{\star *} \\
.000\end{array}$ \\
\hline Neutrophil & $\mathrm{R}$ & & & & & 1 & $\begin{array}{l}-.272^{\star *} \\
.000\end{array}$ & $\begin{array}{l}.182^{\star \star} \\
.003\end{array}$ \\
\hline Platelet & $\mathrm{R}$ & & & & & & 1 & $\begin{array}{l}-.280^{\star *} \\
.000\end{array}$ \\
\hline $\mathrm{Hb}$ & $\mathrm{R}$ & & & & & & & 1 \\
\hline
\end{tabular}

** Correlation is significant at the 0.01 level (2-tailed).

* Correlation is significant at the $0.0 f$ level (2-tailed).

R: Pearson correlation

P: P-Value

\section{Discussion}

COVID-19 is a cryptic disease that it could enable sickness ranging from a cold to cytokine storm and acute respiratory syndrome(6). To date, there is no specific treatment for COVID-19 and few data on the predictive variables of COVID-19 were obtained $(16,17)$. Therefore, diagnose of disease by measuring inflammatory mediators might help clinicians in identifying patients with poor prognosis at earlier stage (18). Present study demonstrated comprehensive data on the clinical, laboratory and image features of patients with nonsevere and severe COVID-19 in Kohgiluyeh and Boyer Ahmad (K\&B) province.

In our data set of COVID-19, we revealed significant differences in positive chest CT scans and positive RTPCR results, when comparing subjects with severe COVID-19 and hyper inflammation with those who did not show expression of hyper inflammation. The results from this review in similarly to other studies from Duan et al(19), Poortahmasebi et al (20), and Udugama et al.(21), indicate that the chest CT scan and RT- 
PCR should be used for symptomatic and hospitalized covid19 patients. In the study by Tao et al, in the epidemic area, chest CT scan in comparison with RT-PCR, maybe a more reliable, practical, and rapid method to diagnose COVID-19(22). According to the latest guidelines released by the Chinese government, Chest CT scan is a common imaging tool for pneumonia diagnosis, and the key indicator for the confirmation of the diagnosis of COVID-19 is based on RT-PCR or sequencing of the gene for respiratory or blood specimens $(20,22)$. However, a rate of $10-40 \%$ RT-PCR false-negative results made this technique insufficient for proper detection $(20,23)$. We suggest a major obstacle for this low efficacy might be related to sampling errors, markedly inappropriate timing of sampling, which is reflected by variations in viral load in upper versus lower respiratory tract.

In a recent study on patients with COVID-19 in K\&B province, our data reported a higher rate of IL- 6 in patients with infection than in the general population. Probably, this findings indicate that IL- 6 cytokine was positively associated with the severity of COVID-19. In accordance with present study, Coomes et al. suggested that in patients with COVID-19, IL-6 levels are significantly elevated and associated with noxious clinical subsequences including: ICU admission, asthma, and death (24). In the analysis by Zhang et al. IL6 level in patients with COVID-19 have dramatically enhanced (25). Similarly, in research by Ruan et al. reported higher levels of IL-6 in COVID-19 patients compared to non-patients(26). Overall, elevations in IL-6 levels between patients with COVID-19 were identified in all previous studies $(13,27-29)$. This suggests that dynamic changes in level of IL- 6 can be used as a diagnosis factor in patients with severe COVID-19 and also, the progression of COVID-19 to complexed disease may be the result of an over-response of the immune system to inflammatory mediators.

In our study cohort, data analysis revealed that there was a high significant levels of ferritin in COVID-19 patients compared to that of non-COVID-19 patients. Similar observations have been reported by scientists from China, Italian and the United States. In Yehuda et al. study, high levels of Ferritin (hyperferritinemia) has been associated with increased illness severity and adverse outcomes, including COVID-19(30). In the study with Guan et al, Ferritin was significantly elevated in more severe cases of COVID-19 Compared with control group (19). Accordance with retrospective cohort study by Zhou, et al, serum ferritin levels have been increased in non-survivors patients with COVID-19 from Wuhan as compared with survivors.(31). About ferritin, Wu et al. reported that higher serum ferritin was related with ARDS development and was able to predict an increased risk of COVID-19 illness(28). Recently, some scientific secrets by Ruscitti et al reported. they discovered the role of the $\mathrm{H}$-chain of ferritin in activating macrophages (macrophage activating syndrome; MAS) to increase the secretion of inflammatory cytokines and cytokine storms in COVID-19 patients. (32). Overall, in accordance with previous studies, it turns out that elevated ferritin concentrations play a critical role in innate immunity and associated with an increase in production of special signaling molecules of the body(13). These studies complete our understanding of the pathogenesis of the high levels of ferritin including the infection with Covid-19, and may contribut clinicians to apply more aggressive treatment for those patients.

In the our study, COVID-19 severe cases had elevated levels of hematological indices (except for Platelet), compared with non-severe cases. The results showed, the COVID-19 can cause some hematological 
indices changes between cases. Several studies have shown the common presenting hematological manifestations of COVID-19. Wu et al. retrospectively demonstrated risk factors for the clinical outcomes of COVID-19 pneumonia and death in China patients. The study showed that several factors related to the development of disease which included, neutrophils, lymphocyte and etc (28). Guan et al. found that lymphocyte had significantly increased in most patients of COVID-19, while platelets had decreased (19). In Huang et al. research, COVID-19 infection is associated with alterations in the WBC and lymphocyte count(33). In Dawei et al study, Compared COVID-19 patients received ICU care with non-ICU patients who had significantly elevated neutrophil and WBC count, as well as lymphocyte were significantly decreased(34). Interestingly, Hu Yun et al. showed that among Covid-19 Positive Patients, the platelet count during the disease course were decreased(35). Similarity, Lippi et al. was showed that a low platelet count correlated with higher disease severity(36). So, the Results of this study reported the changes in hematological markers in covid-19 patients might help to developed the pathophysiology Knowledge of this disease and provide early guids to diagnosis of coronavirus based on routine laboratory tests.

We have some limitations in this study. There were not complete clinical information for all patients with COVID-19 diseases admitted to Jalil hospital during the study term. The study was conducted with limited sample size, therefore, we were unable to do a multivariate analysis and generalize the results. There may also be a selection bias when identify factors that influence the clinical outcomes.

We have an opinion that the findings of this epidemiological study, in a region in southeast of Iran with a high number of COVID-19 cases, was one of the strengths of the present study.

\section{Conclusion}

In conclusion, inflammatory markers especially IL-6 and Ferritin and hematological parameters (WBC, Lymphocyte, Neutrophil, Platelet and $\mathrm{Hb}$ ) were positively correlated with the severity of COVID-19. Measurement of IL-6, Ferritin and hematological indices might be workable tests to diagnosis, monitoring and prognosis of patients with COVID-19.

\section{Declarations}

\section{Ethics approval and consent to participate}

The Research project (No. 990000) was approved by the Ethic Committee of Yasuj University of medical sciences; IR.YUMS. REC.1399.003. Informed consent form was obtained from all subjects.

\section{Consent for publication}

Informed consent was obtained from all Subjects. This Informed Consent Form had two parts:

Information Sheet (to share information about the study).Certicate of Consent (for signatures if participants choose to participate). 
Availability of data and material

The datasets used and/or analysed during the current study are available from the corresponding author on reasonable request.

\section{Competing interests}

none declared

\section{Conflicts of Interest}

The authors have no actual or potential conflict of interest to declare in relation to this study.

\section{Funding}

This work was supported by the Yasuj University Medical Science for the state support of scientific research.

\section{Contribution Author}

Parviz Yazdanpanah and Jalal Pouranfard conceived the study hypothesis. Farzad Vafaei and Sajad Afrouz, designed the study and undertook the literature search, study selection and data abstraction. Saeed javidan sirat and Sajad Afrouz, analyzed the data. All authors interpreted the data, wrote the manuscript, and edited the manuscript critically for important intellectual content.

\section{Acknowledgement}

This manuscript was extracted from the Research project. The authors therefore thank the vice chancellery of research and technology at Yasuj University Medical Science, Iran, for the financial support. The authors are grateful to the Head of Jalil Hospitaldeans for their collaboration in the study.

\section{References}

1. de Wit E, van Doremalen N, Falzarano D, Munster VJ. SARS and MERS: recent insights into emerging coronaviruses. Nature Reviews Microbiology. 2016;14(8):523. https://doi.org/10.1038/nrmicro.2016.81 .

2. Lovato A, de Filippis C, Marioni G. Upper airway symptoms in coronavirus disease 2019 (COVID-19). American Journal of Otolaryngology. 2020. https://doi.org/10.1016/j.amjoto.2020.102474 .

3. Gupta KK, Khan MA, Singh SK. Constitutive inflammatory cytokine storm: a major threat to human health. Journal of Interferon \& Cytokine Research. 2020;40(1):19-23. https://doi.org/10.1089/jir.2019.0085.

4. Lucena-Silva N, Torres LC, Luna CF, de Barros Correia J, da Silva GAP. The balance between the serum levels of IL- 6 and IL-10 cytokines discriminates mild and severe acute pneumonia. BMC pulmonary medicine. 2016;16(1):170. https://doi.org/10.1186/s12890-016-0324-z . 
5. Magrone T, Magrone M, Jirillo E. Focus on Receptors for Coronaviruses with Special Reference to Angiotensin-converting Enzyme 2 as a Potential Drug Target-A Perspective. Endocrine, Metabolic \& Immune Disorders Drug Targets. 2020. https://doi.org/10.2174/1871530320666200427112902 .

6. Kruse RL. Therapeutic strategies in an outbreak scenario to treat the novel coronavirus originating in Wuhan, China. F1000Research. 2020;9. https://doi.org/10.12688/f1000research.22211.1 .

7. Tanaka T, Narazaki M, Kishimoto T. IL-6 in inflammation, immunity, and disease. Cold Spring Harbor perspectives in biology. 2014;6(10):a016295. https://doi.org/10.1101/cshperspect.a016295.

8. Vaninov N. In the eye of the COVID-19 cytokine storm. Nature Publishing Group; 2020. https://doi.org/10.1038/s41577-020-0305-6 .

9. Jaramillo-Rocha V. Acute Respiratory Distress Syndrome. The New England journal of medicine. 2017;377(19):1903-4. https://doi.org/10.1056/nejmc1711824 .

10. Ye Q, Wang B, Mao J. The pathogenesis and treatment of theCytokine Storm'in COVID-19. The Journal of infection. 2020. https://doi.org/10.1016/j.jinf.2020.03.037 .

11. Gabay C. Interleukin-6 and chronic inflammation. Arthritis research \& therapy. 2006;8(2):S3. https://doi.org/10.1186/ar1917 .

12. O'Neill L, McCormick J, Gao W, Veale DJ, McCarthy GM, Murphy CC, et al. Interleukin-6 does not upregulate pro-inflammatory cytokine expression in an ex vivo model of giant cell arteritis. Rheumatology advances in practice. 2019;3(1):rkz011.https://doi.org/10.1093/rap/rkz011.

13. Liu T, Zhang J, Yang Y, Zhang L, Ma H, Li Z, et al. The potential role of IL-6 in monitoring coronavirus disease 2019. Available at SSRN 3548761. 2020. https://doi.org/10.2139/ssrn.3548761 .

14. Wang $M$, Zhou Y, Zong Z, Liang Z, Cao Y, Tang H, et al. A precision medicine approach to managing 2019 novel coronavirus pneumonia. Precision Clinical Medicine. 2020;3(1):14-21. https://doi.org/10.1093/pcmedi/pbaa002 .

15. Yi Y, Lagniton PN, Ye S, Li E, Xu R-H. COVID-19: what has been learned and to be learned about the novel coronavirus disease. International journal of biological sciences. 2020;16(10):1753. https://doi.org/10.7150/ijbs.45134 .

16. Miao M, De Clercq E, Li G. Clinical significance of chemokine receptor antagonists. Expert Opinion on Drug Metabolism \& Toxicology. 2020;16(1):11-30. https://doi.org/10.1080/17425255.2020.1711884.

17. Jin J-M, Bai P, He W, Wu F, Liu X-F, Han D-M, et al. Gender differences in patients with COVID-19: Focus on severity and mortality. Frontiers in Public Health. 2020;8:152. https://doi.org/10.3389/fpubh.2020.00152.

18. Kermali M, Khalsa RK, Pillai K, Ismail Z, Harky A. The role of biomarkers in diagnosis of COVID-19-A systematic review. Life Sciences. 2020:117788. https://doi.org/ 10.1016/j.lfs.2020.117788.

19. Guan W-j, Ni Z-y, Hu Y, Liang W-h, Ou C-q, He J-x, et al. Clinical characteristics of coronavirus disease 2019 in China. New England journal of medicine. 2020;382(18):1708-20. https://doi.org/10.1016/j.jinf.2020.03.041.

20. Poortahmasebi V, Zandi M, Soltani S, Jazayeri SM. Clinical Performance of RT-PCR and Chest CT Scan for Covid-19 Diagnosis; a Systematic Review. Advanced Journal of Emergency Medicine. 
2020;4(2s):e57-e. https://doi.org/10.22114/ajem.v4i2s.459.

21. Udugama B, Kadhiresan P, Kozlowski HN, Malekjahani A, Osborne M, Li VY, et al. Diagnosing COVID19: the disease and tools for detection. ACS nano. 2020;14(4):3822-35.

https://doi.org/10.1021/acsnano.0c02624.

22. Ai T, Yang Z, Hou H, Zhan C, Chen C, Lv W, et al. Correlation of chest CT and RT-PCR testing in coronavirus disease 2019 (COVID-19) in China: a report of 1014 cases. Radiology. 2020:200642. https://doi.org/10.1148/radiol.2020200642.

23. Tahamtan A, Ardebili A. Real-time RT-PCR in COVID-19 detection: issues affecting the results. Taylor \& Francis; 2020. https://doi.org/10.1080/14737159.2020.1757437.

24. Coomes EA, Haghbayan H. Interleukin-6 in COVID-19: a systematic review and meta-analysis. MedRxiv. 2020. https://doi.org/10.1002/rmv.2141.

25. Zhang C, Wu Z, Li J-W, Zhao H, Wang G-Q. The cytokine release syndrome (CRS) of severe COVID-19 and Interleukin-6 receptor (IL-6R) antagonist Tocilizumab may be the key to reduce the mortality. International journal of antimicrobial agents. 2020:105954. https://doi.org/10.1016/j.ijantimicag.2020.105954.

26. Ruan Q, Yang K, Wang W, Jiang L, Song J. Clinical predictors of mortality due to COVID-19 based on an analysis of data of 150 patients from Wuhan, China. Intensive care medicine. 2020;46(5):846-8. https://doi.org/10.1007/s00134-020-06028-z.

27. Chen L, Liu H, Liu W, Liu J, Liu K, Shang J, et al. Analysis of clinical features of 29 patients with 2019 novel coronavirus pneumonia. Zhonghua jie he he hu xi za zhi= Zhonghua jiehe he huxi zazhi= Chinese journal of tuberculosis and respiratory diseases. 2020;43:E005-E. https://doi.org/10.3760/cma.j.issn.1001-0939.2020.0005.

28. Wu C, Chen X, Cai Y, Zhou X, Xu S, Huang H, et al. Risk factors associated with acute respiratory distress syndrome and death in patients with coronavirus disease 2019 pneumonia in Wuhan, China. JAMA internal medicine. 2020. https://doi.org/10.1001/jamainternmed.2020.0994.

29. Huang Y, Tu M, Wang S, Chen S, Zhou W, Chen D, et al. Clinical characteristics of laboratory confirmed positive cases of SARS-CoV-2 infection in Wuhan, China: A retrospective single center analysis. Travel medicine and infectious disease. 2020. https://doi.org/10.1016/j.tmaid.2020.101606.

30. Shoenfeld Y. Corona (COVID-19) time musings: Our involvement in COVID-19 pathogenesis, diagnosis, treatment and vaccine planning. Autoimmun Rev. 2020;19(6):102538-. https://doi.org/10.1016/j.autrev.2020.102538.

31. Zhou F, Yu T, Du R, Fan G, Liu Y, Liu Z, et al. Clinical course and risk factors for mortality of adult inpatients with COVID-19 in Wuhan, China: a retrospective cohort study. The lancet. 2020. https://doi.org/10.1016/ S0140-6736(20)30566-3.

32. Ruscitti P, Berardicurti O, Cipriani P, lagnocco A, Shoenfeld Y. Severe hyper-inflammatory COVID-19, another piece in the puzzle of the "htperferritinemic syndrome". Rheumatol Point View. 2020. https://doi.org/10.1016/j.autrev.2020.102569. 
33. Huang C, Wang Y, Li X, Ren L, Zhao J, Hu Y, et al. Clinical features of patients infected with 2019 novel coronavirus in Wuhan, China. The lancet. 2020;395(10223):497-506. https://doi.org/10.1016/S01406736(20)30183-5.

34. Wang D, Hu B, Hu C, Zhu F, Liu X, Zhang J, et al. Clinical characteristics of 138 hospitalized patients with 2019 novel coronavirus-infected pneumonia in Wuhan, China. Jama. 2020;323(11):1061-9. https://doi.org/10.1001/jama.2020.1585.

35. Yun H, Sun Z, Wu J, Tang A, Hu M, Xiang Z. Laboratory data analysis of novel coronavirus (COVID-19) screening in 2510 patients. Clinica Chimica Acta. 2020. https://doi.org/10.1016/j.cca.2020.04.018.

36. Lippi G, Mattiuzzi C. Hemoglobin value may be decreased in patients with severe coronavirus disease 2019. Hematology, Transfusion and Cell Therapy. 2020. https://doi.org/10.1016/j.htct.2020.03.001. 